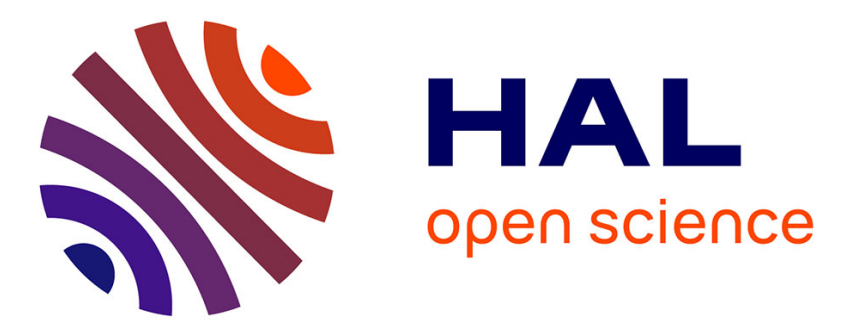

\title{
A Customizable Lean Design Methodology for Maritime
}

\author{
Brendan P. Sullivan, Monica Rossi, Sergio Terzi
}

\section{To cite this version:}

Brendan P. Sullivan, Monica Rossi, Sergio Terzi. A Customizable Lean Design Methodology for Maritime. 15th IFIP International Conference on Product Lifecycle Management (PLM), Jul 2018, Turin, Italy. pp.508-519, 10.1007/978-3-030-01614-2_47 . hal-02075592

\section{HAL Id: hal-02075592 \\ https://hal.inria.fr/hal-02075592}

Submitted on 21 Mar 2019

HAL is a multi-disciplinary open access archive for the deposit and dissemination of scientific research documents, whether they are published or not. The documents may come from teaching and research institutions in France or abroad, or from public or private research centers.
L'archive ouverte pluridisciplinaire HAL, est destinée au dépôt et à la diffusion de documents scientifiques de niveau recherche, publiés ou non, émanant des établissements d'enseignement et de recherche français ou étrangers, des laboratoires publics ou privés. 


\title{
A Customizable Lean Design Methodology for Maritime
}

\author{
Brendan P. Sullivan ${ }^{1}$, Monica Rossi ${ }^{1}$, and Sergio Terzi ${ }^{1}$ \\ ${ }^{1}$ Department of Management, Economics and Industrial Engineering - Politecnico di Milano, \\ via Lambruschini 4/B, Milan 20156, Italy \\ brendan.sullivan@polimi.it, monica.rossi@polimi.it, sergio.terzi@polimi.it
}

\begin{abstract}
Lean focuses on the reduction of wastes, optimization of processes and consideration of the production of highly customized systems. Over the past decade the maritime industry has been working to apply unique solutions capable of improving their design and development performances by focusing heavily on production time and quality, however work and progress has been limited due to the competitive nature of the market [1]-[4]. Despite efforts, design methodologies applied in the industry have remained rather unchanged, regardless of demand for the incorporation of new technologies and materials. Literature and multiple case studies were utilized to develop a design methodology, that aims to transform the design process into a lean process that is measurable and capable of addressing multiple areas of improvement. Through a holistic lean transformation methodology developed through this work, sociotechnical variables were incorporated to allow for maritime vessel designers to customize the method to overcome unique deficiencies. The paper describes the approach and work being undertaken as well as outlines the Lean Design Methodology for Maritime.
\end{abstract}

Keywords: Vessel Design, Maritime Design, Shipbuilding, Lean Design, Lean Transformation, LTF

\section{Introduction}

Technological innovation and economic growth are closely related, and the ability to conquer them will facilitate the continued growth and development of European industries. Globally, the maritime industry continues to be a hugely important part of the economy due to the delivery of valuable raw material, components and finished products [5], [6]. The maritime industry is the backbone of global trade there are critical areas that must be advanced to leverage technological and social capabilities [7].

Surrounded by 136,000 km of coastline, a blue economy of 5.4 million jobs and almost $€ 500$ billion a year of gross added value, Europe has traditionally been a world leader in the maritime activities. Like other industries it has become increasingly important for companies to improve their processes to maintain competitiveness, prosperity, and survival. European maritime industry faces constant competition, as ports represent strategic poles of distribution for traffic to/from emerging countries.

The maritime industry has been working to apply unique solutions capable of improving their development performances [4]. To remain competitive, Europe needs to identify and develop new value-added solutions, products and services that can accommodate the changing demands. Focusing on industrial repositioning, by incorporating new technologies and materials that are unfamiliar to many of the engineering and design practices in the industry today (i.e. tools, methods, techniques).

This paper introduces a customizable lean design methodology that was developed alongside industry partners to reduce design time, and wastes encountered in the design 
of maritime vessels. To achieve this, a case study methodology was used to contribute to state of the art based on 3 industrial cases active in the design/development and manufacturing of maritime vessels in Europe.

\section{State of Art and Practice}

We investigated how design in the maritime industry was managed and how lean has been previously applied. Literature was in accordance to the research approach evaluated to provide a review of design principles, approaches, and tools, suitable for the maritime industry and capable of resolving deficiencies identified.

\subsection{Lean Design and Development}

The original definition of lean thinking aims at "Creating more value, defined from the customer's perspective, while consuming fewer resources” [8]. Lean design is an aspect and consideration of product development that facilitates, impacts and allows for the realization of products. When appropriately considered in early-stage design decisions, the incorporation of lean tools and processes has proven capable to improve system lifecycle value and system performance, while reducing waste. Systems are being designed to operate with longer lifecycles in rapidly changing environments, there is a shift from traditional mission centric optimization strategies to complex systems that are robust, and value optimized, requiring improved methods of delivering value. The creation of value in lean product and process development consists of enabling the whole enterprise to generate everything the customer is willing to pay to establish operations that produce and deliver quality products [10].

\section{Lean in the Maritime Industry.}

The publication of lean in shipbuilding is limited due to the novelty and the restriction of the concept, particularly related to the approaches being employed. However, process efficiency, delay rectification and cost control are all principal areas where work has been undertaken and measured improvement has been demonstrated [2], [11], [12]. According to [1] elements of lean can be found throughout the industry however there are few organizations that utilize lean principles in an organized manner.

The maritime industry has been working to advance vessel development approaches by focusing heavily on production time and quality [1]-[4]. A key difference between automotive companies that have adopted skills/approaches and methods from the Toyota and the maritime industry is that in general vessel design and development prohibits the utilization of assembly lines since vessels are designed and developed in limited or single cases. Features that characterize the shipbuilding industry focus primarily on the design and development of complex one-of-a-kind products [13], [14]. Lean vessel design and development is a very specialized, field of lean and is seen as "one of the extensions beyond Lean Construction' ' [15].

\subsection{Maritime Design Process}

Vessel design is a complex, iterative and multifaceted process, influenced by a number of factors (both internal and external) [16]. Depending on the vision or requirements set forth by the customer, designers are required to develop cost efficient vessels capable of performing specific tasks, while maintaining strict adherence to both 
international and national rules or regulations. However, finding the best balance within these restrictions is a challenge for the designer, system integrator, and the ship yard.

The vessel design type has a strong influence on the design choices and the design process that will be undertaken from conception to final customer delivery, due to both customer expectations and legal rules/regulations. One of the most common vessel design processes is the spiral design process. The vessel design spiral is a conceptual model of a process for maritime vessel design [17]. The establishment of requirements is the first step of this process and is a fundamental starting point before entering the concept design phase, leading to preliminary power estimations, a propulsion system, hull shape, and preliminary cost estimations. Within each phase of the process, solutions become specific and options are set, culminating in a design ready for authorization. Incremental development and improvement have been developed and applied to maritime. One approach is PDCA (plan-do-check-act or plan-do-check-adjust) which is a four-step method used for the control and continual improvement of processes and products, another variation is OPDCA, which incorporates observation.

\section{Research Approach}

The research covered in this paper utilized a case study method which was selected due to its ability to facilitate a close examination of the lean design process in the maritime industry. Through a multiple-case design, it was possible to acquire and analyze data during a real-time project from various perspectives.

In addition, product design state of art was applied to develop a comprehensive methodological foundation that included elements of lean systems engineering, and lean design. The literature reviewed was identified and evaluated based on relevancy to lean design, lean product and process development and product development.

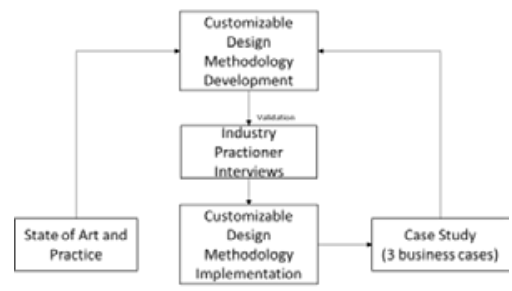

Fig. 1. Research Approach

In each case, interviews and on-site visits were undertaken to understand how the companies design maritime vessels. Through the identification of existing practices as well as the incorporation of best practices identified through literature, a lean design methodology was constructed based on the unique needs and expectations of the maritime cases. From there, a comprehensive list of steps and sub-procedures are introduced into design process to improve efficiency and reduce waste within the cases.

\section{$4 \quad$ Empirical Research}

The authors performed an empirical research study in Europe with multiple cases from March 2017 to February 2018. The cases were studied based on three areas: (a) context understanding and data gathering, (b) identify design challenges, and measures for analysis, and (c) strategy setting where business needs were elicited. 
The design process, wastes and lean tools were evaluated in 3 different cases in Europe, who are all active in the design and development of maritime vessels. This allowed for different design processes, tool and issues related to the design process to be evaluated at multiple levels. In each case there was an opportunity to interview employees with similar experience, and the design process was able to be observed.

\subsection{Classification Structures}

Development of maritime vessels is a considerable challenge for engineering and design professions, with different challenges expected depending on the levels of complexity inherent to the vessels. The industry tends to be dominated by the experience and expertise of engineering, and customization is understood in several areas of the industry as a promising approach to compete in the fragmented market. By using flexible processes and organizational structures, customization enables companies to provide variety and individualized solutions. The cases were classified in Fig. 2 according to businesses classification (1) business size [18], (1a) operating structure, and vessel classification (2) Sea-Related Sector [19], and (2a) vessel type [20], [21].

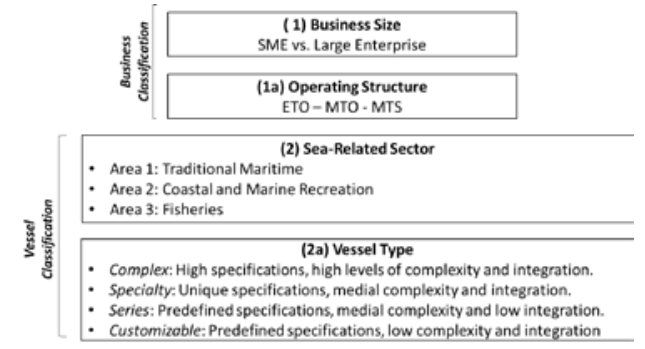

Fig. 2. Classification of Case Study

\subsection{Interview}

Interviews were conducted using a reference questionnaire, comprised of 33 questions identified through literature and best practices. At each case, the technical director (or delegate) was interviewed, lasting roughly 3 hours. Information about the company and its products and markets was also collected, in addition using open resources (web site, databases, etc.). In all cases, secondary interviews were conducted to clarify design and industrial positioning, this semi-structured interview lasted 1hour.

\begin{tabular}{|l|l|l|l|}
\hline Case & Business Classification & \multicolumn{2}{|c|}{ Vessel Classification } \\
\hline Case \#1 & SME; ETO & Area 1: Traditional Maritime Sector & Series Vessel \\
\hline Case \#2 & SME; ETO & Area 1: Traditional Maritime Sector & Series Vessel \\
\hline Case \#3 & SME; ETO & Area 1: Traditional Maritime Sector & Specialty Vessel \\
\hline
\end{tabular}

Table 1. Case Study Classification and Characteristics

\subsection{Interview Analysis}

Data was categorized to determine the design process maturity in each of the 3 cases and the average used as an initial benchmark [22]:

1. Organization (blue textbox) how people are involved in daily activities: Work Organization), coordination of people and activities, roles of engineers and designers (Roles and Coordination), skills/expertise of practitioners (Skills and Competences).

2. Process (Yellow textbox) how NPD is performed, based on four areas: design rules and methodologies (Methods), control mechanisms and improvement of the process 
(Process Management), how decisions are taken every day (Decision Making Factors) and competitors and customers (Activities and Value).

3. Knowledge Management (light blue textbox) how companies create, share, represent and re-use tacit and explicit knowledge: Formalization (how knowledge is formalized and shared) and Computerization (how IT tools and platforms are used for supporting knowledge storing, sharing and reusing along the NPD process).

Based on the maturity level established by the CLIMB assessment method, efficacy of the practice was determined [22], [23].

\begin{tabular}{|c|c|c|c|c|}
\hline $\begin{array}{c}0-20 \% \\
\text { Chaos }\end{array}$ & $\begin{array}{c}21-40 \% \\
\text { I nw }\end{array}$ & $\begin{array}{c}41-60 \% \\
\text { Intermediate }\end{array}$ & $\begin{array}{c}61-80 \% \\
\text { Mature }\end{array}$ & $\begin{array}{c}81-100 \% \\
\text { Best Practice }\end{array}$ \\
\hline
\end{tabular}

Fig. 3. CLIMB Maturity Levels [22]

For each of the process maturity levels being evaluated the questions were scored using a Likert scale (5 points scale; 1,3,5,7,9), so the respondent could choose if their company's practice level. The lowest levels scored with 1 correspond to a poor practice, while the highest-level cane be scored 9 which corresponds to a best practice. The score for each area was calculated using an additive scale (summing the single scores of the questions describing the area) then normalized in \% [23]. The following formula according to the CLIMB method was utilized to score each generic area $\left(\mathrm{A}_{\mathrm{i}}\right)$ :

Where:

$$
\mathrm{a}_{\mathrm{i}}=\frac{\sum_{1}^{\mathrm{m}_{\mathrm{i}}} \mathrm{q}_{\mathrm{ij}}}{8 * \mathrm{~m}_{\mathrm{i}}}
$$

$a_{i}$ is the score corresponding to $\mathrm{i}$-th area, expressed in \%

$i=1 \ldots 8$, is the indicator for the areas

$q_{i j}$ is the score of the answer to the question $\mathrm{j}$, belonging to the i-th area

$j=1 \ldots m_{i}$, is the indicator for the questions, depending on the area the number of questions changes

$m_{i}$, is the number of questions of the $\mathrm{i}$-th area

$8^{*} m_{i}$ is the maximum score the area can assume in the case the respondent declares

\begin{tabular}{|c|l|l|l|}
\hline Case & \multicolumn{1}{|c|}{ Organizational ML } & \multicolumn{1}{|c|}{ Process ML } & \multicolumn{1}{c|}{ Knowledge Mgmt. ML } \\
\hline Case \#1 & (Mature) $67.8 \%$ & (Intermediate) 58.9\% & (Intermediate) 55.7\% \\
\hline Case \#2 & (Mature) $74.3 \%$ & (Mature) 65.3\% & (Mature) 75.7\% \\
\hline Case \#3 & (Mature) 69.8\% & (Intermediate) $56.1 \%$ & (Intermediate) $55.2 \%$ \\
\hline Average & (Mature) $70.6 \%$ & (Intermediate) $60.1 \%$ & (Mature) $62.2 \%$ \\
\hline
\end{tabular}

Table 2. Case Study Maturity Level according to CLIMB

The level of maturity achieved in each area of analysis is represented in the radar chart (Fig. 4) to show a picture of the level of implementation in each area of the analysis (Table 2) and displays the positioning of the company related to the corresponding CLIMB maturity level (\%). The highest levels of maturity were found in Case 2, and in Organization, as seen in Table 2, the absolute average maturity score was $64.08 \%$. 


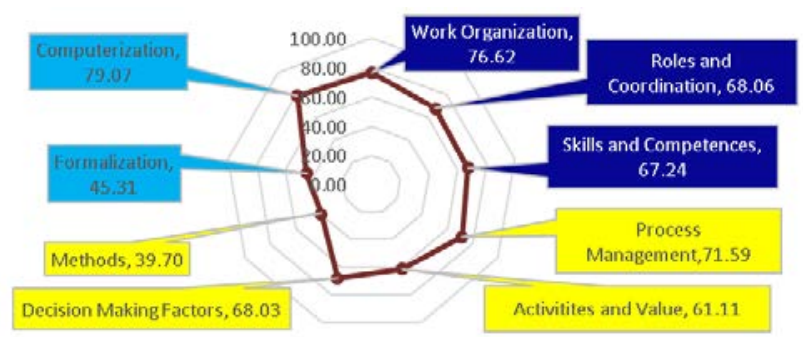

Fig. 4. Average Interview Management Process Radar Chart

\subsection{Waste Analysis}

The waste analysis served as a tool applied for methodological development and as a component within the greater lean objectives. This analysis required designers/engineers categorically associate a series of information to translate waste in the design process focusing on: cause, effect, severity, probability, detectability, detection way and avoidability. Examples of waste are: too many meetings organized inside company, time spent for bad definition of priorities and inability to reuse previous knowledge.

\begin{tabular}{|l|l|l|}
\hline & Area & Description \\
\hline W1 & Change Priorities & Time making changes, reviews, modifications and reworks \\
\hline W2 & Reworks - Incomplete Data & $\begin{array}{l}\text { Projects (of parts of projects) must be re-done due to incorrect, } \\
\text { incomplete, unreliable data, information, specifications, test, etc. }\end{array}$ \\
\hline W3 & $\begin{array}{l}\text { Non-Necessary Product } \\
\text { Functionalities }\end{array}$ & Functionalities and features that are not necessary or required. \\
\hline W4 & Knowledge Retrieval & Difficulty to retrieve and access previous knowledge. \\
\hline W5 & Project Leftovers & Projects are realized that never reach the market. \\
\hline W6 & Manual Data Transcoding & $\begin{array}{l}\text { The information and data related to the product and project need } \\
\text { to be inserted and coded manually. }\end{array}$ \\
\hline W7 & Missing Authorization & Projects are delayed due to authorizations challenges. \\
\hline W8 & $\begin{array}{l}\text { Defect Products are De- } \\
\text { signed }\end{array}$ & Defective products are introduced; requiring modifications. \\
\hline W9 & No Knowledge Reuse & $\begin{array}{l}\text { Projects, developed in the past, are redone due to previous } \\
\text { knowledge not being retrieved. }\end{array}$ \\
\hline W10 & Over-Engineered Projects & $\begin{array}{l}\text { Over-engineering; cost increase without adding value to the } \\
\text { product. }\end{array}$ \\
\hline
\end{tabular}

Table 3. Waste Analysis Process Areas

Each of the 10 wastes (Table 3) were measured within each case to identify nonvalue-added process and then compared to the average waste within traditional SMEs (production, automotive, services) [24]. In respect to the wastes based on vessel classification commonalities as well as differences can be identified. As seen in Fig. 5 there is a difference between the two classes, with the only common waste being W1 Change Priorities (which is high, however follows the case study average) and W10 Over Engineered Products (which has a low value and is the case average).

Based on the classification of each case, all were found to be SMEs (ETOs) operating within the same sea-related sector, though a variation in the vessel type was noted as shown in Table 1.

While the business classification and sea-related sectors for the Business Cases were the same the vessel classification amongst the three cases were different, there was a distinction related to the vessel classification, however the limited sample size requires further work to be conclusive. Recognizing the single case that was classified under 
this criterion there remains a level of bias that will require additional cases (wastes) to be measured before a definitive interpretation can be made at that level.

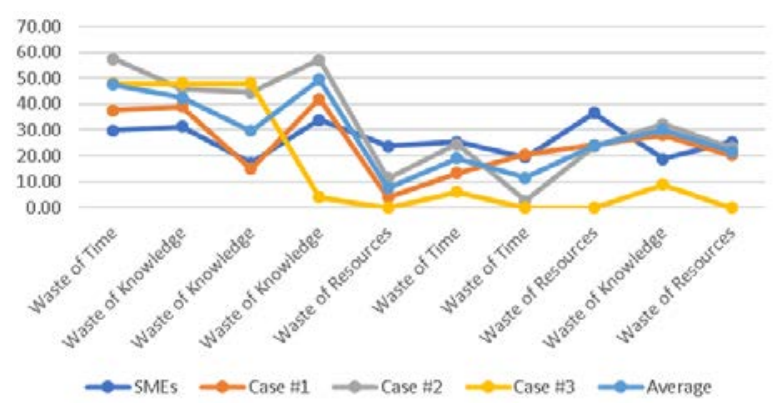

Fig. 5. Waste Analysis Within Each Case

\section{Customizable Lean Design for Maritime}

To achieve a lean transformation in maritime design it is necessary for three aspects to be considered: : process, people, and technology, which are all interrelated and interdependent, collectively affecting an organization's ability to achieve goals and objectives [25].As shown above, the traditional design process has areas of low maturity that can be strengthened through the inclusion of lean and can only be rectified through a lean transformation. The methodology employs a holistic approach since each phase of the development process must to be considered. The cases used in this research stressed a need for improvements that could reduce costs and times in the design and development process through a comprehensive, long-term, improvement methodology. The Customizable Lean Design Methodology was developed to address the lean management of design processes through the reduction of wastes in the industry through a sequential structure of decision-making.

Based on the outputs of the use case interview and waste analysis high-level and functional requirements were used to ensure the methodology addressed necessary objectives. High-level requirements mandate the considerations and behaviors that are to be addressed in the Customizable Lean Design Methodology for Maritime Industry. While functional requirements were established to mandate how the Customizable Lean Methodology addressed these established behaviors.

\subsection{Maritime Lean Transformation}

Like product development which deals with information and processes, involving a multitude of choices and iterations that are used for problem solving and decision-making activities. The maritime industry is confronted with the management of iterations and complex development, and through the development of unique solutions the customizable lean design methodology aims at improving development performances. To facilitate the optimization of this initiative, an evaluation of diffused strategies was undertaken to develop a Lean Transformation Framework (LTF), that seeks to maximize value while minimizing waste and resources in a sustainable and environmentally conscious manner. LTF was introduced by the Lean Institute by John Shook to combat delays and complications being faced in implementation of lean [26]. 


\subsection{Practices and Approaches for Maritime Lean Transformation}

Within this study, the authors identified more than 24 best practices proposed in literature to establish a multidimensional lean transformation. Practices and approaches were identified based on the objectives of the LTF to confirm suitability to deliver skills and improvements based on business and industrial objectives.

The methods and practices focus on the outputs they can facilitate based on highlevel requirements set by the 3 cases. The outputs adopted correspond to the five areas of improvement related to the LTF and ultimately are comprised of several different yet interrelated elements that facilitated the establishment of multifunctional teams, the use of modularization and standardization for parts and components, and the use of design for $\mathrm{x}$. Through this process, an easy-to-implement methodology was developed that allows businesses to adapt the methodology to satisfy their specific needs. The methods, practices and approaches focus on the outputs they facilitate. The outputs adopted, correspond to the outputs generated from the case interviews and waste analysis to visualize how methods and practices relate to LTF principles.

\subsection{Customizable Lean Design Methodology for the Maritime Industry}

The Customizable Lean Design Methodology targets SMEs in the maritime vessel design and engineering sector, that are seeking to improve or implement lean into their organization to reduce time for development and waste within the process. The methodology offers a customizable set of tasks and steps that can be easily modified to facilitate the successful implementation of lean in various maritime design process.

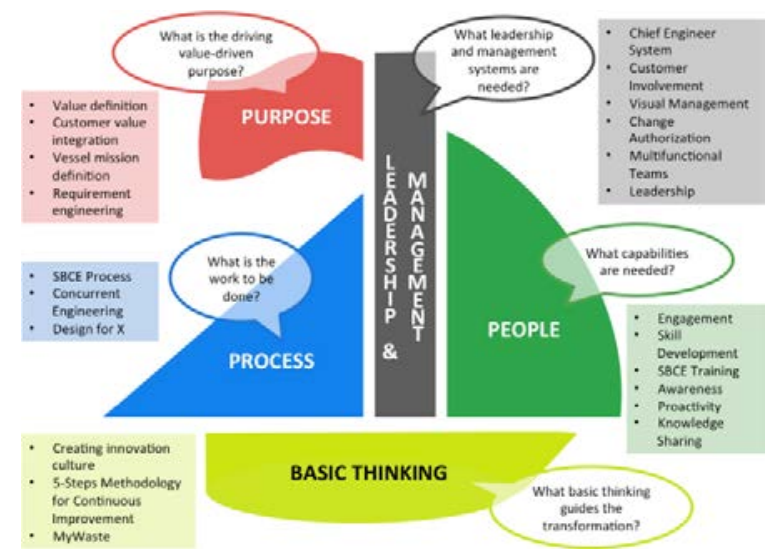

Fig. 6. Customizable Lean Transformation Methodology for Maritime

The methodology was built based on organizational objectives and case study commitments to deliver and increase stakeholder value. Through a series of questions, rather than explicit steps, the LTF methodology for maritime focuses on obtaining support within the organization to promote a path for continuous improvement in the design process by addressing [26], [27].

- Purpose: What is the value for the stakeholder?

- Process: How the industry/organization can better deliver value?

- People: What skills, attributes, or characteristics are needed/required to engage in these processes to best deliver value to the stakeholder? 
- Leadership and Management: What is the management system and leader behaviors utilized to achieve goals and objectives?

- Basic thinking: What considerations and values/goals can guide the transformation?

The methodology is committed to deliver and increase stakeholder value through the 5 concurrently lean aspects, presented above. To customize the methodology, consideration of each aspect must take place to explain the main objectives of the case and the most appropriate means to reduce design time and facilitate the total lean transformation. Collectively this supports the definition and design of new vessels in an innovative, efficient, eco-friendly and cost-effective manner.

\section{Discussion, Conclusion and Future Work}

This paper aimed to introduce a lean transformation methodology that is customizable and easily implementable in the maritime industry. The methods and processes introduced support the adoption and implementation of lean in the design of maritime vessels as well as techniques that can be relevant to specific vessel types. Based on design processes and waste analysis best practices were positioned, to allow for unique wastes throughout the industry to be targeted. The is expected to give designers a complete view of the design process and abridge the duration of implementation.

This methodology seeks to extend the advantages of lean to a new area of the industry to improve the Value Added of SME offerings. Designed to be easily customizable, the methodology provides a solution for organizational lean transformation that respects people and integrates knowledge sharing, feedback and continual improvement into the design process. Following the development of the customizable lean design methodology a series of interviews with experts in the field were utilized to confirm the methodology, relating to context, objectives, and ability to be implemented. Post-interview adjustments to the methodology were then used to strengthen the customizable methodology regarding 'process' so that multiple areas of knowledge generation could be leveraged through simulation and knowledge-based engineering approaches. KPIs will be later developed to measure the improvements provided by the methodology.

While the methodology is generally applicable to the design process of vessels in the Traditional Maritime Sector, the methodology will require broader application and implementation to verify its efficacy and ability to be applied to the design of different vessel types. Particularly, it can't be stated at present that all the findings related to vessel types are conclusive. Additional studies will be needed to understand if the use of the methodology and best practices are context dependent. Currently, validation and implementation (process improvement measurements) of the methodology are underway and additional cases are being identified to extend the data evaluation process.

\section{Acknowledgments}

The content of this paper is based on the LINCOLN project (EU H2020 727982) that is currently under development (www.lincolnproject.eu). We wish to express our deep gratitude to all LINCOLN partners.

\section{References}

[1] J. Liker and T. Lamb, "Lean Shipbuilding, , June," in Ship Production Symposium, Ypsilanti, MI, 2001. 
[2] P. C. Koenig, H. Narita, and K. Baba, "Lean Production in the Japanese Shipbuilding Industry ?," J. Sh. Prod., vol. 18, no. 3, pp. 167-174, 2002.

[3] I. Radovic and B. J. Macclaren, "Lean Six Sigma in Shipbuilding,” in European Shipbuilding and Repair Conference on November 2, 2004 in London, 2004.

[4] V. Milanovic, "Application of set-based concurrent engineering to shipbuilding projects," Norwegian University of Science and Technology, 2016.

[5] European Commission, "Report on the Blue Growth Strategy: Towards more sustainable growth and jobs in the blue economy,” SWD/2017/128 Final, pp. 1-62, 2017.

[6] J. J. Corbett and J. Winebrake, "The Impacts of Globalisation on International Maritime Transport Activity,” in Global Forum on Transport and Environment in a Globalising World, 2008.

[7] B. Ki-moon, "Maritime Transport Is 'Backbone of Global Trade and the Global Economy', Says Secretary-General in Message for International Day.” 2016.

[8] J. P. Womack and D. T. Jones, Lean thinking: banish waste and create wealth in your corporation. Simon \& Schuster, New York, 1996.

[9] J. P. Womack and D. T. Jones, The Machine that Changed the World. New York: Rawson Associates, 1990.

[10] M. Rossi, J. Morgan, and J. Shook, “Lean Product and Process Development,” in The Routledge Companion to Lean Management, 2017.

[11] R. L. Storch, S. Lim, R. L. E. E. Storch, and S. Lim, "Improving flow to achieve lean manufacturing in shipbuilding I mproving - ow to achieve lean manufacturing in shipbuilding,” Prod. Plannning Control, vol. 7287, no. November, 1999.

[12] S. L. St, N. D. St, A. H. St, T. D. St, D. L. St, and S. C. St, “Shipbuilding and Lean Manufacturing - A Case Study,” Soc. Nav. Archit. Mar. Eng., no. 201, 2001.

[13] K. K. Longva, "Warehouse Management in a Lean Shipbuilding Perspective - An Exploratory Case Study of Ulstein Verft,” Høgskolen Molde, 2009.

[14] O. Salem, J. Solomon, A. Genaidy, and I. Minkarah, "Lean Construction: From Theory to Implementation,” J. Manag. Eng., vol. 22, no. 4, 2006.

[15] K. . Dugnas and I. Uthaug, "Can Lean Philosophy Strengthen and Develop Cluster Advantages? An Exploratory Research towards Lean Shipbuilding,” 2007.

[16] C. Vossen, R. Kleppe, and S. Randi, "Ship Design and System Integration,” no. September, 2013.

[17] F. Mistree, W. F. Smith, B. A. Bras, J. K. Allen, and D. Muster, "Decision-Based Design: A Contemporary Paradigm for Ship Design,” Soc. Nav. Archit. Mar. Eng. Annu. Meet., vol. seminar, p. seminar, 1990

[18] E. European Commission, "What is an SME," Internal Market, Industry, Entrepreneurship and SME, 2018. [Online]. Available: http://ec.europa.eu/growth/smes/business-friendlyenvironment/sme-definition_en.

[19] P. R. Corporation, "The role of Maritime Clusters to enhance the strength and development of maritime sectors,” 2008.

[20] D. Kolić, "LEAN MANUFACTURING METHODOLOGY FOR SHIPYARDS," BRODOGRADNJA, vol. 63, pp. 18-29, 2012.

[21] H. M. Gaspar, A. M. Ross, D. H. Rhodes, and S. O. Erikstad, "Handling Complexity Aspects in Conceptual Ship Design,” Int. Mar. Des. Conf., no. June, pp. 1-14, 2012.

[22] M. Rossi, S. Terzi, and M. Taisch, "Engineering and Design Best Practices in New Product Development : an Empirical Research," Procedia CIRP, vol. 21, p. 2, 2014.

[23] M. Rossi and S. Terzi, "CLIMB: maturity assessment model for design and engineering processes," Int. J. Prod. Lifecycle Manag., vol. 10, no. 1, 2017.

[24] M. Rossi, E. T. Kerga, M. Taisch, and S. Terzi, "Proposal of a method to systematically identify wastes in New Product Development Process,” 2011 17th Int. Conf. Concurr. Enterprising, no. Ice, pp. 1-9, 2011.

[25] J. Morgan and J. K. Liker, No The Toyota Product Development System: Integrating People, Process, and Technology. 2006.

[26] J. Shook, “The Lean Transformation Framework," The Lean Enterprise Institute, 2018.

[27] M. Rossi, M. Taisch, and S. Terzi, "Lean product development: A five-steps methodology for continuous improvement,” 2012 18th Int. Conf. Eng. Technol. Innov. ICE 2012 - Conf. Proc., 2012. 